\title{
Repeated cesarean section and vaginal delivery after cesarean section in São Paulo State in 2012
}

Karoline Honorato Brunacio 1

iD https://orcid.org/0000-0001-6330-4341

Zilda Pereira da Silva 2

(iD https://orcid.org/0000-0003-4648-113X

1 Departamento de Nutrição. Anhanguera Educacional LTDA. Av. Dr. João Batista de Souza Soares, 4121. São José dos Campos, SP, Brasil. CEP: 12.236-660. E-mail: karoline.brunacio@usp.br

2 Faculdade Saúde Pública. Universidade de São Paulo. São Paulo, SP, Brasil.

\begin{abstract}
Objectives: describe mothers, pregnancies and newborns'characteristics according to the type of childbirth history and to analyze repeated cesarean section (RCS) and vaginal delivery after cesarean section (VBACS), in São Paulo State in 2012.

Methods: data are from the Sistema de Informações sobre Nascidos Vivos (Live Birth Information Systems). To find the RCS's group, the current type of childbirth equal to cesarean section was selected and from these all the previous cesareans. To identify the $V B A C S$ 's group all live birth with current vaginal delivery were selected and from these all previous cesareans. Mothers with a history of RCS and VBACS were analyzed according to the characteristics of the pregnancy, newborn and the childbirth hospital.

Results: 273,329 mothers of live birth with at least one previous child were studied. $43 \%$ of these were born of RCS and 7.4\% of VBACS. Mothers who underwent RCS are older and higher educated and their newborns presented a lower incidence of low birth weight. Early term was the most frequent rating for gestational age born of RCS. Live births were of VBACS and had greater proportions of late term. The RCS was more common in hospitals not affiliated with the Sistema Único de Saúde (SUS) (Public Health System) (44.1\%).

Conclusion: the high RCS's rates, especially in the private sector, highlight the necessity of improvements in childbirth care model in São Paulo.

Key words Repeated cesarean section, Vaginal birth after cesarean, Cesarean section, Childbirth, Public Health System
\end{abstract}

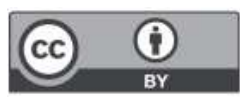




\section{Introduction}

Cesarean section is a procedure to be performed in situations where maternal-fetal conditions do not favor vaginal delivery, and as in any surgical intervention it is not free of potential complications. However, it has been progressively increasing worldwide and is considered endemic in Brazil.1-3

In Brazil, overall cesarean section rates have increased from $38 \%$ in 2001 to $48.8 \%$ in 2008 in several States, and in the private health sector they range from $80 \%$ to $90 \% .1-3$ The excessive use of cesarean sections results in increased costs, higher maternal and newborn morbidity and mortality and among others. $1-4$

The increase in cesarean sections is not only because of clinical recommendations or to improve perinatal outcomes. Among the factors associated with cesarean sections, the occurrence of prior cesarean stands out as one of the major determinants of procedure in Brazil 5 and worldwide. 6

A number of studies point out to the relationship between repeated cesarean sections and risks to the mother's and fetus' health. The risks of placenta previa, placental accretism and uterine rupture increase within future pregnancies. ${ }^{2}$ In addition to these adverse effects, there is an increased incidence of perinatal complications (reduced fetal growth and premature birth) in pregnancies after cesarean sections. ${ }^{3}$

Although, most childbirths performed in women with a history of previous cesarean section are surgical, high rates of vaginal deliveries with low incidence of complications are observed in patients with previous cesarean section. ${ }^{3}$ Review studies tend to support these findings. ${ }^{6}$ Similarly, the Department of Health and Human Services of the U.S. Agency for Healthcare Research and Quality give strong evidence that vaginal delivery after cesarean section (VBACS) is a reasonable and safe choice for most women. ${ }^{7}$

The Federação Brasileira das Sociedades de Ginecologia e Obstetrícia (FEBRASGO) (Brazilian Federation of Gynecological and Obstetric Societies) suggest that a decision for vaginal delivery in a pregnant woman with a prior cesarean section is appropriate, as long as there is intensive labor monitoring. FEBRASGO and the Ministry of Health only recommend elective cesarean section when there is more than one prior cesarean section or in case of absolute contraindication for vaginal delivery. 4,8

Given the above and considering that the excess of cesarean sections in Brazil is an important public health issue and has been a major challenge for the maternal and child health area, the objective was to describe the mothers, pregnancies and newborns' characteristics, according to the type of childbirth history, with emphasis on the analysis of mothers who underwent repeated cesarean section and vaginal delivery after cesarean.

\section{Methods}

This is a cross-sectional, population-based study, based on secondary data from the Sistema de Informações sobre Nascidos Vivos (SINASC) (Live Birth Information System) and the Cadastro Nacional de Estabelecimentos de Saúde (CNES) (National Register of Health Establishments) collected from the São Paulo State Secretary of Health.

The SINASC was implemented in the 1990s by the Brazilian Ministry of Health in order to obtain the profile of live births. The system data entry form is the Declaração de Nascido Vivo (DNV) (Certificate of Live Births), which contains variables for the definition of the epidemiological profile of live births, besides allowing the analysis of mothers, pregnancies and newborns' characteristics. ${ }^{9}$ Since its implementation, the DNV form has undergone some changes, aimed at its improvement. In the form prior to 2011, it was not possible to identify the types of childbirth of previous pregnancies; however, in the new DNV form, the fields are introduced as "number of vaginal deliveries" and "number of cesarean deliveries", which allows a better knowledge of the mother's reproductive history.

The study population refers to live births (LB) residing in São Paulo State, born in health facilities, of non primiparous women, registered in SINASC in 2012.

The total of 618,933 LBs in 2012, the following were not eligible: those with registered document by the old DNV version $(58,257)$, those of non-residents and residents giving birth outside of São Paulo State $(3,943)$, those born outside the health facilities $(1,583)$, those from primiparous mothers $(251,910)$ and those of multiple gestations $(7,086)$. Multiple gestations were excluded because twin gestation is an acceptable medical reason for performing a cesarean section. ${ }^{2}$ Records with lack of information such as, type of childbirth (522) and history of previous pregnancies $(20,219)$ were also excluded, remaining 275,403 LBs.

These records were linked to the CNES, based on the code of the health establishment and, in its absence, on the name of the establishment and the address of occurrence was registered in the DNV. 
Seventy four registrations $(0.03 \%)$ without a valid CNES code were excluded, resulting in a study population of $275,329 \mathrm{LBs}$ of single gestation and multiparous mothers.

To find the group of mothers with a history of repeated cesarean section (RCS), the cesarean section as a type of current childbirth was selected and then all the results with previous cesarean section were searched for in the birth history. To identify the group of mothers who had vaginal delivery after cesarean section, all LBs with current vaginal delivery were selected and from these, all the results with previous cesarean section were identified (Figure 1).

The rate of VBACS among women with a history of cesarean section was calculated according to the following formula10: (Number of LB of vaginal delivery of women with previous cesarean section) / (total of LB from women with a previous cesarean section) $\times 100$. The RCS rate among women with a history of cesarean section was calculated as follows 10: (Number of LB by cesarean section of women with a previous cesarean section) / (total of LB among women with a previous cesarean section) $\times 100$.

The following characteristics were analyzed: mother's age group $(<20,20$ to 34,35 years old and older), mother's schooling (no schooling, complete elementary school and incomplete elementary school; complete high school and incomplete high school; complete higher education and incomplete higher education; and more), marital status ("with partner": married or stable union and "without partner": single, widowed, legally separated/ divorced), mother's race/color (white, black, Asian, mixed or indigenous), parity (number of previous pregnancies, number of vaginal deliveries and number of cesarean deliveries), birth weight (low birth weight: up to 2,499 grams, normal birth weight: from $2,500 \mathrm{~g}$ to $3,999 \mathrm{~g}$ and high birth weight: equal $\geq 4,000 \mathrm{~g}$ ), gestational age (very preterm: $<32$ weeks, moderate preterm: $32-36$ weeks, early term: 37-38 weeks, full term: 39-40 weeks, late term: 41 weeks and post-term: $>41$ weeks), number of prenatal visits (none, from 1 to 3 , from 4 to 6 and 7 or more), trimester that started prenatal care ( 1 st, $2^{\text {nd }}$ and 3 rd trimesters), fetal presentation (cephalic pelvic/podalic or transverse) and the affiliation of the birth hospital with the Sistema Único de Saúde (SUS) (Brazilian Public Health System) (SUS, mixed and private).

Data was described in the form of frequencies measurements of the variables of interest, whose differences were verified by the chi-square test. To verify the differences between means, the variance of analysis (ANOVA) test was used. A 5\% significance level was adopted for the statistical tests. Data processing and analysis were performed with the PASW/SPSS software version 17.0.

The research used a public domain database without individual identification, the project was submitted and the need of approval was waived by the Research Ethics Committee of the Faculdade de Saúde Pública of the Universidade de São Paulo.

\section{Results}

Of the 273,329 mothers' of LB with at least one previous child, almost $56 \%$ were born of cesarean section, which $43 \%$ were by RCS and $13 \%$ by cesarean after vaginal delivery (CAVD), indicating that mothers of LBs with a history of cesarean section have a higher chance $(\mathrm{PR}=3.26$; CI95\% $=3.23-3.29 ; p<0.0001)$ of being born also by cesarean section (data not shown). As for the $44.1 \%$ LBs of vaginal delivery, $36.7 \%$ were by repeated vaginal delivery (RVD) and a small number (7.4\%) were born of VBACS.

It was found that mothers who underwent RCS are older and more educated, almost $20 \%$ having complete higher education, while among those with VBACS, only $5.4 \%$ reached this level of schooling (Table 1).

Approximately two thirds of the mothers with RCS were reported as being white, while half of those with RVD were black (51.7\%). It is also worth noting that mothers with RCS are those with the highest proportion of marital status "with partner" $(68.1 \%)$ and the lowest $(3.0 \%)$ of multiparous women (5 or more children), unlike those with VBACS, which had the highest proportion of multiparous women (8.8\%). All differences in proportions were statistically significant (Table 1).

The higher proportion of low birth weight in the group CAVD (10.7\%) draws attention. Upon stratification of LBW infants by gestation age (GA), a higher proportion of very preterm and preterm infants was observed in the CAVD group (66.8\%) than among the other groups (RCS $=59.3 \%$, VBACS $=59.4 \%$ and $\mathrm{RVD}=54.8 \%$ ). The differences in proportions and means were statistically significant (Table 1)

As for the characteristics of prenatal care and childbirth, initiation of prenatal care in the first trimester occurred in almost $84 \%$ of RCS cases, almost 10 percent more than in mothers with vaginal delivery. Similarly, 7 or more prenatal visits were more frequent in the RCS group (78.6\%), a propor- 
tion of almost 15 percentage points higher than in the VBACS group (63.8\%). All differences in proportions were statistically significant.

It is noted that $85.3 \%$ of the women with at least one previous cesarean section had RCS. However, in the private health system, this proportion reaches $95.7 \%$. The proportion of women with at least one previous cesarean section who had a VBACS is almost 15 in 100 . The analysis by type of hospital shows that this value reaches $28.7 / 100$ women in the public hospitals and only 4.3 in private hospitals. Mixed hospitals have an intermediate situation with 13.4 in every 100 women with at least one prior cesarean section undergoing VBACS (Table 2).

Regarding to delivery characteristics, the cephalic presentation of the LBs was widely present in all groups, being $95.2 \%$ in the RCS group, $91 \%$ in the CAVD, $97.4 \%$ in the VBACS and $99.3 \%$ in the RVD. Labor was induced in only $8.7 \%$ of the repeated cesarean group, almost six times less than in the vaginal delivery groups $(\mathrm{VBACS}=50.1 \%$;
$\mathrm{RVD}=53.4 \%$ ). Cesarean section occurred before labor started in $70.4 \%$ of RCS cases and $59.2 \%$ of CAVD cases. All differences were statistically significant.

Early term was the most frequent classification for gestational age $(44.3 \%)$ in the RCS group, different from the other groups, which presented more full-term LBs. On the other hand, LBs of VBACS showed higher proportions $(6.3 \%)$ of late term than those in the RCS group (4.1\%). The differences were statistically significant (Table 1).

The differences in gestational age classification according to gestational history can be seen in Figure 2. It can be seen that LBs of cesarean section have curves more to the left, indicating shorter gestation duration than in vaginal deliveries.

RCS was more frequent in private hospitals (44.1\%), unlike vaginal deliveries, which were more than $60 \%$ in public hospitals. Figure 3 shows the differences between the four groups and type of birth hospital, with cesarean sections being more frequent

Figure 1

Diagram of type of delivery history and final groupings.

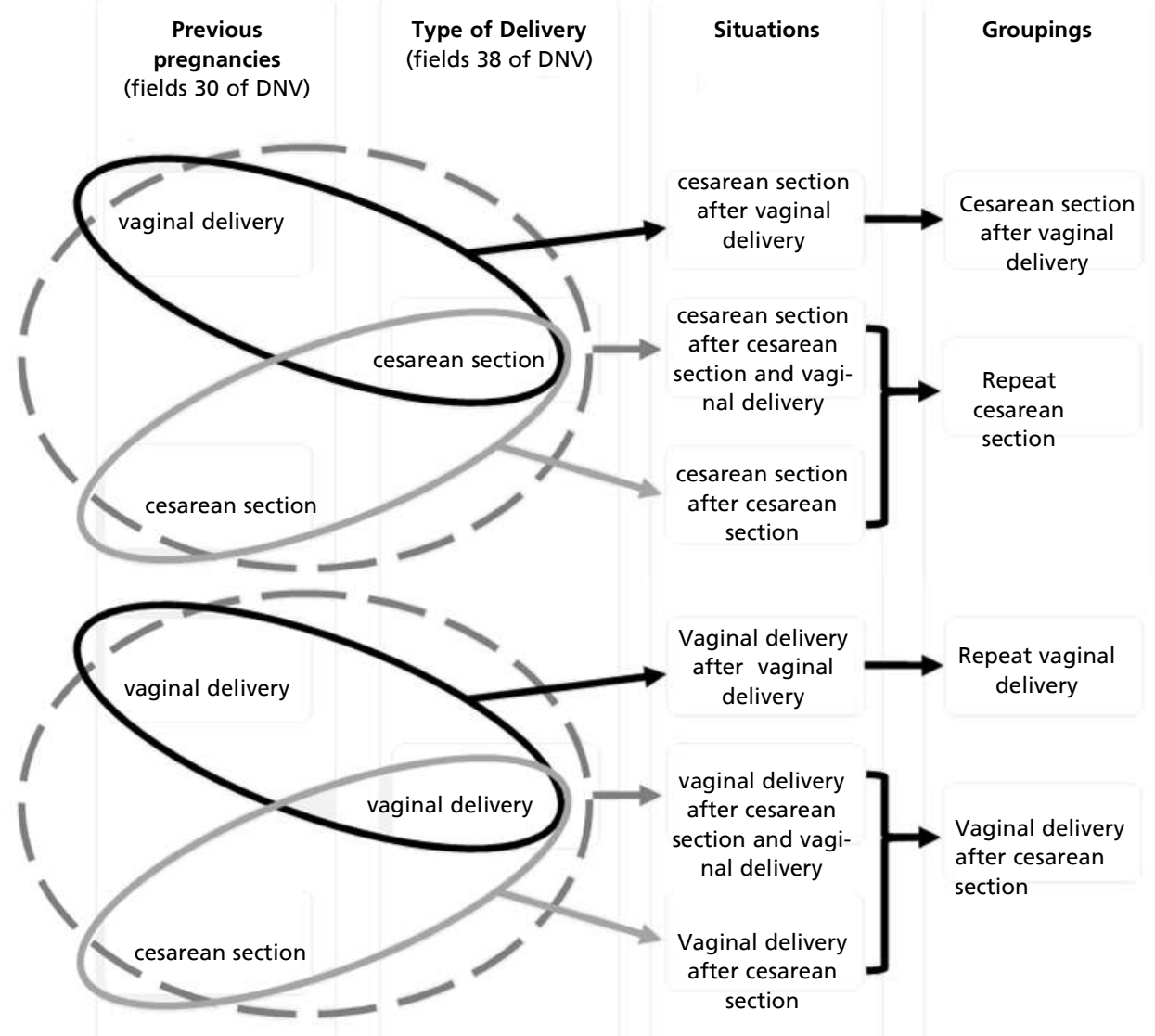


Live births, according to the characteristics of the mothers, the newborn, gestational age and type of delivery history. São Paulo State, 2012

\begin{tabular}{|c|c|c|c|c|c|}
\hline \multirow[t]{2}{*}{ Variables } & \multicolumn{4}{|c|}{ Type of delivery history** } & \multirow[b]{2}{*}{ Total } \\
\hline & RCS & CAPD & VBACS & RVD & \\
\hline \multicolumn{6}{|l|}{ Mother's age group* (years old) } \\
\hline$<20$ & $2.80 \%$ & $2.80 \%$ & $5.50 \%$ & $7.10 \%$ & $4.60 \%$ \\
\hline$\geq 35$ & $25.20 \%$ & $23.20 \%$ & $17.30 \%$ & $14.10 \%$ & $20.30 \%$ \\
\hline Mean & 30.3 & 30 & 28.5 & 27.7 & 29.2 \\
\hline \multicolumn{6}{|l|}{ Mother's schooling* } \\
\hline Up to incomplete elementary school & $16.20 \%$ & $22.90 \%$ & $28.10 \%$ & $29.90 \%$ & $23.00 \%$ \\
\hline Complete higher education and more & $19.60 \%$ & $8.40 \%$ & $5.40 \%$ & $3.70 \%$ & $11.20 \%$ \\
\hline \multicolumn{6}{|l|}{ Mother's marital status* } \\
\hline With partner & $68.10 \%$ & $60.80 \%$ & $54.70 \%$ & $52.60 \%$ & $60.50 \%$ \\
\hline \multicolumn{6}{|l|}{ Mother's race/color* } \\
\hline White & $65.20 \%$ & $55.90 \%$ & $49.20 \%$ & $47.20 \%$ & $56.20 \%$ \\
\hline Black*** & $34.00 \%$ & $43.50 \%$ & $49.90 \%$ & $51.70 \%$ & $42.90 \%$ \\
\hline \multicolumn{6}{|l|}{ Parity* } \\
\hline Up to 2 & $80.50 \%$ & $77.90 \%$ & $67.70 \%$ & $72.00 \%$ & $76.10 \%$ \\
\hline 5 and more & $3.00 \%$ & $4.70 \%$ & $8.80 \%$ & $7.10 \%$ & $5.10 \%$ \\
\hline \multicolumn{6}{|l|}{ Birth weight* $(\mathrm{g})$} \\
\hline Mean & $3,232.60$ & $3,181.60$ & $3,152.00$ & $3,195.50$ & $3,206.00$ \\
\hline Low birth weight $(\leq 2,499 \mathrm{~g})$ & $6.30 \%$ & $10.70 \%$ & $8.40 \%$ & $6.90 \%$ & $7.20 \%$ \\
\hline High birth weight $(\geq 4,000 \mathrm{~g})$ & $5.60 \%$ & $7.00 \%$ & $3.70 \%$ & $4.20 \%$ & $5.10 \%$ \\
\hline \multicolumn{6}{|l|}{ Gestational age* } \\
\hline Preterm $(<36)$ & $11.00 \%$ & $14.70 \%$ & $12.80 \%$ & $11.50 \%$ & $11.70 \%$ \\
\hline Term $(37-41)$ & $86.80 \%$ & $82.50 \%$ & $83.90 \%$ & $85.20 \%$ & $85.40 \%$ \\
\hline Late term $(>41)$ & $2.20 \%$ & $2.80 \%$ & $3.40 \%$ & $3.40 \%$ & $2.80 \%$ \\
\hline \multicolumn{6}{|l|}{ Trimester that started prenatal care* } \\
\hline 1st trimester & $83.9 \%$ & $82.7 \%$ & $74.4 \%$ & $74.7 \%$ & $79.7 \%$ \\
\hline \multicolumn{6}{|l|}{ Number of prenatal visits* } \\
\hline None & $1.00 \%$ & $1.00 \%$ & $3.50 \%$ & $2.40 \%$ & $1.70 \%$ \\
\hline From 1 to 3 & $3.20 \%$ & $3.90 \%$ & $8.70 \%$ & $8.00 \%$ & $5.50 \%$ \\
\hline From 4 to 6 & $17.20 \%$ & $19.00 \%$ & $24.00 \%$ & $24.50 \%$ & $20.60 \%$ \\
\hline 7 or more & $78.60 \%$ & $76.20 \%$ & $63.80 \%$ & $65.10 \%$ & $72.30 \%$ \\
\hline \multicolumn{6}{|l|}{ Fetal presentation* } \\
\hline Cephalic & $95.2 \%$ & $91.0 \%$ & $97.4 \%$ & $99.3 \%$ & $96.4 \%$ \\
\hline
\end{tabular}

${ }^{*} p<0.05$ (for proportions, chi-square test; for means, ANOVA).

$* \star R C S=$ repeated cesarean section; $C A V D=$ cesarean after vaginal delivery; VBACS = vaginal birth after cesarean section; $\mathrm{RVD}=$ repeated vaginal delivery.

$* * *$ Black race/color represents the sum of black plus mixed.

in private hospitals and vaginal deliveries more frequent in those linked to public system.

\section{Discussion}

The issue of cesarean section has been widely discussed, especially in Brazil due to its high frequency and growing trend. Several factors explain its occurrence, among them the presence of a previous cesarean section. In the present study, it was observed that mothers of LBs with a history of cesarean section have a higher chance of being born of cesarean section, which corroborates the findings in Brazilian 5 and foreign 6 maternity hospitals.

Repeated cesarean sections were the most frequent in the study population (42.9\%), indicating the magnitude of the phenomenon in Brazil, which has been considered a public health problem since 
Table 2

Repeated cesarean section and vaginal birth after cesarean section rate, according to the affiliation of the birth hospital with the Brazilian Public Health System (SUS). São Paulo State, 2012.

\begin{tabular}{lccccc}
\hline $\begin{array}{l}\text { Affiliation of the } \\
\text { hospital with } \\
\text { the SUS }\end{array}$ & $\begin{array}{c}\text { Mothers' of live births } \\
\text { of previous } \\
\text { cesarean section }\end{array}$ & \multicolumn{3}{c}{ RCS } & \multicolumn{3}{c}{ Type of delivery history* } \\
\cline { 3 - 5 } & & $\mathrm{N}$ & Rate/100 & $\mathrm{N}$ & RBACS/100 \\
\cline { 3 - 5 } & 44,352 & 31,606 & 71.3 & 12,746 & 28.7 \\
\hline Public & 39,805 & 34,477 & 86.6 & 5,328 & 13.4 \\
Mixed & 54,365 & 52,044 & 95.7 & 2,321 & 4.3 \\
Private & 138,522 & 118,127 & 85.3 & 20,395 & 14.7 \\
Total & & & & \\
\hline
\end{tabular}

SUS = Brazilian Public Health System (Sistema Único de Saúde).

${ }^{*} \mathrm{RCS}=$ repeated cesarean section; VBACS = vaginal birth after cesarean section.

Figure 2

Live births, according to the type of delivery and gestational age. São Paulo State, 2012.

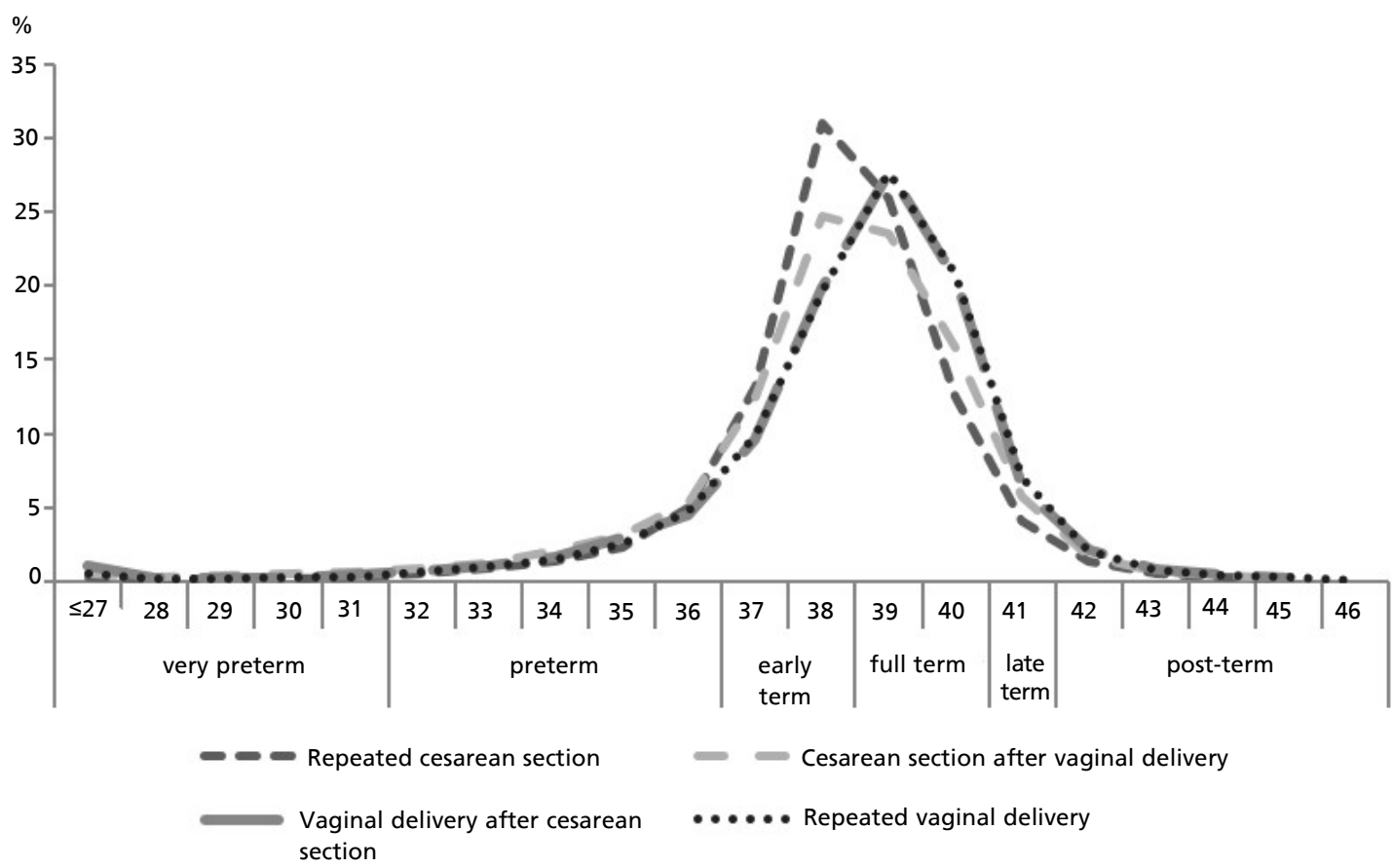

the 1980 s when rates doubled in a decade. 1,2 Studies indicate that if only the necessary cesarean sections were performed, there would be a global saving of about US\$2 billion per year and a large reduction of mother and child morbidity and mortality.2,11

The RCS group profile showed that mothers are on average older and more educated than in the other groups, especially in private hospitals. Several studies on cesarean sections, including primiparous, point out their association with older and more educated mothers. 5 In general, the panorama of fertility in Brazil has pointed out to a continuous reduction in the number of children in all maternal age groups, but marked, in the last decade, by a structure of older fertility and clearly associated with schooling, in another words, as the women's level of schooling increases, they choose to have families later in life. 12

Authors have demonstrated that the higher the number of repeated cesarean sections, the higher the 
Live births, according to the affiliation of the birth hospital with the Brazilian Public Health System (SUS). São Paulo State, 2012.

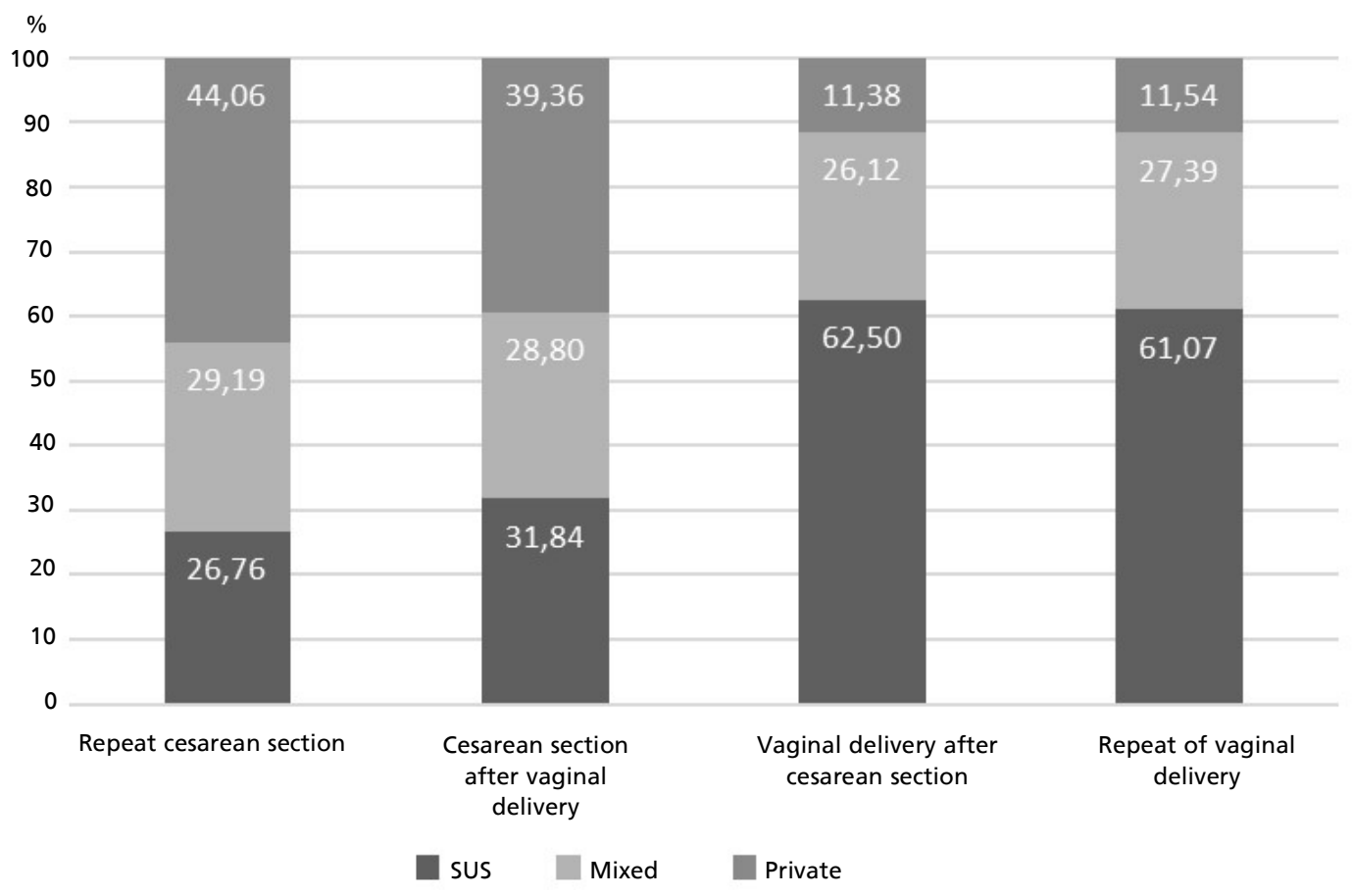

SUS = Brazilian Public Health System (Sistema Único de Saúde).

risk of maternal morbidity.3,13 A systematic review study concluded that severe maternal morbidity progressively increased according to the number of previous cesarean sections. ${ }^{13}$ Similarly, in a Brazilian study, an association between maternal near miss (woman who almost died, but survived a complication that occurred during pregnancy, childbirth or up to 42 days of termination of pregnancy) and history of previous cesarean section 14 was observed.

Despite the implications mentioned, the present study found that among mothers' of LBs with at least one prior cesarean section, $85.3 \%$ were born of RCS, which places prior cesarean section as an important possible causal factor in determining a new cesarean section. This proportion was slightly higher than the one found in Australia in $2008(83.2 \%)^{15}$ and lower than in the U.S. in 2007 (92\%). 16

However, a previous cesarean section does not necessarily automatically lead to a new cesarean section, that is to say, according to the Ministry of Health, a vaginal delivery in a pregnant woman with a previous cesarean section may be appropriate, provided there is intensive labor monitoring and the patient is informed about the risks. ${ }^{8}$ Thus, in the present study among mothers' of LBs with prior cesarean section, almost $15 \%$ were born of VBACS. A similar proportion was found in the study Nascer no Brasil (Born in Brazil) (14.8\%), 17 which was lower than that found in a study conducted in Australia in $2008(16.7 \%)^{15}$ but higher than that found in the United States in 2007 (8.3\%). ${ }^{16}$

The type of birth at the hospital is also an important factor on the observational level of VBACS. This procedure was much more frequent in public hospitals than in mixed or private hospitals. For mothers with a previous cesarean section, giving birth at a public hospital meant that VBACS was four times more likely than for those who gave birth in the private hospitals. However, in this study, factors that could influence the contraindication of VBACS were not controlled.

Many studies have analyzed the advantages and consequences of labor after cesarean section and repeated cesarean section, although the results are conflicting and not definitive.18-20 Authors found higher rates of uterine rupture and perinatal mortality in women with labor after cesarean section 
$(0.47 \%$ and $0.13 \%$, respectively) compared to those who underwent elective repeated cesarean section $(0.03 \% \text { and } 0.05 \%)^{18}$ and the rates of needing blood transfusion, uterine infection and hypoxic encephalopathy in the group with repeated cesarean section were lower. ${ }^{2}$ A review study identified that the risk of perinatal mortality, bag valve mask ventilation and perinatal asphyxia was higher during labor in the after cesarean section group. 19

On the other hand, findings show that there was no increase in postpartum hemorrhage, vaginal tears or neonatal complications in mothers who underwent VBACS when comparing them to nulliparous women in spontaneous or induced labor. $20 \mathrm{~A}$ review study found that, although rare, maternal mortality was significantly higher for repeated elective cesarean sections $(0.013 \%)$ compared to labor after cesarean section $(0.004 \%) .18$ In another review, it was found that infants from repeated cesarean sections are more likely to present transient tachypnea. ${ }^{19}$ Finally, some types of maternal and perinatal morbidity are higher in repeated cesarean sections and other types of morbidities are higher in labor after cesarean section. Overall labor after cesarean section can be a reasonable choice for most women. $3,7,18$

Regarding to the type of fetus presentation, cesarean section is only recommended in cases of fetal malposition, such as in transverse and breech positions. Still, the best route of delivery in breech position is controversial, and there is evidence that in selected patients and trained physicians for this purpose, vaginal delivery is a good option. However, in cases of induction of labor after a previous cesarean section, a non-cephalic fetal presentation is considered an absolute contraindication. 2,3 However, in this study, $95.2 \%$ of LBs from repeated cesarean sections had cephalic presentation (ideal for vaginal delivery), although, this variable alone does not justify the route of the delivery chosen.

Another possible justification for part of the number of cesarean sections is that macrosomic fetuses or fetuses with growth restriction results in relative contraindication for labor induction after cesarean delivery.2,3 Thus, in our study a small portion, $5.6 \%$ and $6.3 \%$, of RCS cases could be justified by the fact that LBs had high and low birth weight, respectively.

In addition, another possible cause for the high proportion of cesarean sections may be intrapartum tubal sterilization. Up to the end of the $1980 \mathrm{~s}$, surgical sterilization was prohibited in Brazil - with rare exceptions. 21 Thus, cesarean sections were often used to illegally perform and cover up the additional cost of this procedure. ${ }^{21}$ However, even after the Ministry of Health regulated and established rules for tubal ligation - such as prohibiting it during childbirth $^{2}$ - studies show that the practice of intrapartum sterilization still persists, and there is an association between cesarean deliveries and tubal sterilization. ${ }^{22}$

Prematurity has been associated with cesarean section.2,23 From data of the study Nascer no Brasil, it was observed that in private hospitals with standard care, most babies born of cesarean section had a GA of 37 or 38 weeks - early terms. 24 Similarly, in Australia, most elective cesarean sections in term babies were performed with a GA between 37 and 38 weeks. 15 Although, in our study it is not possible to distinguish elective cesarean sections, the same trend was observed, with a higher concentration of early term LBs in the RCS group (44.3\%) and being even higher when considering only the LBs by RCS in private hospitals (54.3\%). One fact that stands out in São Paulo State but is present throughout Brazil, is that one third of cesarean births occur at this gestational age. 25 This is a worrisome situation, since studies show that these LBs have higher risks for morbidity and mortality compared to full-term LBs. 26

Moreover, when studying the adverse effects at different gestational ages of LBs born of repeated cesarean sections, authors found that births at 37 and 38 weeks of gestation had significantly higher risks of adverse neonatal outcome, while births at 39 and 40 weeks of gestation showed better neonatal outcomes compared to continuing pregnancy. ${ }^{27}$

Researchers have concluded that the optimal time for repeated cesarean section is at 39 weeks. In this study, the repeated cesarean group had about $38 \%$ of full-term LBs, the lowest proportion among the groups with different childbirth histories studied.27

Authors show differences in the frequency of cesarean sections and in the mothers profile according to the type of financing of the hospital. 17 In Australia, $15.7 \%$ of multiparous women' childbirth are cesarean in public hospitals and $27.6 \%$ in private hospitals. 28 In Brazil, authors have found twice as high a proportion of cesarean sections among births in private hospitals compared to those in public hospitals 17 This trendy was also observed in the present study: repeated cesarean section rate ranging from $26.6 \%$ in public hospital to $44.1 \%$ in private hospitals.

The Agência Nacional de Saúde Suplementar (ANS) (National Agency for Supplementary Health) recognizes the problem that goes beyond the high 
rates of cesarean sections in the private sector. The scarce autonomy of women in making decisions about how to conduct their delivery and the low adhe-rence to the policies and guidelines proposed by the Ministry of Health regarding labor and birth care is also a problem. In 2015, a project by ANS was created with the support of the Ministry of Health, aiming to encourage the adoption of models of delivery and birth care that provide quality services, enhance normal birth, and contribute to minimize the risks resulting from unnecessary cesarean sections. ${ }^{3}$

Although, authors have experienced good reliability and validity with SINASC data, 29 one limitation is due to the information collection tool: the DNV. Although the DNV has recently been improved, with the insertion of new fields for information, it does not provide information on maternal morbidity, which could be useful to explain the performance of cesarean sections.

RCS was the most frequent means of birth in the present study. We identified a significant proportion of vaginal deliveries that occurred after a previous cesarean section, mainly in public hospitals, whereas RCS is the most frequent in private hospitals. This information indicates that the present situation is influenced by the organization of services at each hospital.

Although, some of the cesarean sections performed are justified and recommended in order to

\section{References}

1. Victora CG, Aquino EML, Leal MC, Monteiro CA, Barros FC, Szwarcwald CL. Saúde de mães e crianças no Brasil progressos e desafios. Lancet. 2011; 377 (9780): 1863-76.

2. Sass N, Oliveira LG. Obstetrícia. 1 ed. Rio de Janeiro: Guanabara Koogan, 2017.

3. Silva CHM, Laranjeira CLS, Osanan GC, Bonomi IBA Manual SOGIMIG de assistência ao parto e puerpério. 1 ed. Rio de Janeiro: Med Book; 2019.

4. Trapani Júnior A, Hillmann BR, Borba KB, Faust LW. Cesárea: indicações e técnicas baseadas em evidências. In Fernandes CE, Sá MFS. Tratado de obstetrícia FEBRASGO - Federação Brasileira das Sociedades de Ginecologia e Obstetrícia. 1 ed. Rio de Janeiro: Elsevier; 2019. p. 917-29.

5. Pádua KS de, Osis MJD, Faúndes A, Barbosa AH, Moraes Filho $\mathrm{OB}$. Fatores associados à realização de cesariana em hospitais brasileiros. Rev Saúde Pública. 2010; 44 (1): 70-

6. Sentilhes L, Vayssière C, Beucher G, Deneux-Tharaux C Deruelle P, Diemunsch P, Gallot D, Haumonté JB, Heimann S, Kayem G, Lopez E, Parant O, Schmitz T, Sellier Y, Rozenberg P, d'Ercole C. Delivery for women with a previous cesarean: guidelines for clinical practice from the save lives, the high rates of repeated cesarean sections, especially in the private sector, highlight the need for adjustments in the model of childbirth care in São Paulo State. Unnecessary interventions are linked to short and long-term maternal and neonatal morbidity and mortality, and consequently to high public health costs. Thus, it is essential that managers and policy makers act to contain and reduce unnecessary interventions in childbirth

\section{Acknowledgments}

We would like to thank the Conselho Nacional de Desenvolvimento Científico e Tecnológico (CNPq) (National Council for Scientific and Technological Development) for the financial support and the São Paulo State Secretary of Health for the provided data.

\section{Authors' contribution}

Brunacio KS and Silva ZP contributed to the conception and design of the study. Brunacio KH performed data analysis and interpretation and prepared drafts of the manuscript. Silva ZP contributed to the analysis and interpretation of data and critically reviewed the manuscript. All authors approved the final version of the article.

French College of Gynecologists and Obstetricians (CNGOF). Eur J Obstet Gynecol Reprod Biol. 2013; 170: $25-32$.

7. Agency for Healthcare Research and Quality of. U.S. Department of Health and Human Services - AHRQ Vaginal Birth After Cesarean: New Insights. Evidence Report/Technology Assessment. Portland; 2010. (AHRQ Publication $n^{\circ} 10-E 003$ )

8. Brasil. Ministério da Saúde. Secretaria de atenção à saúde. Departamento de ações programáticas estratégicas. Gestação de alto risco - Manual técnico ( $5^{\mathrm{a}}$ Ed.). Brasília, DF; 2012.

9. Mello Jorge MHP, Laurenti R, Gotlieb SLD. Análise da qualidade das estatísticas vitais brasileiras: a experiência de implantação do SIM e do SINASC. Ciên Saúde Coletiva. 2007; 12 (3): 643-54

10. MacDorman M, Declercq E, Menacker F. Recent trends and patterns in cesarean and vaginal birth after cesarean (VBAC) deliveries in the United States. Clin Perinatol. 2011:38; 179-92

11. Gibbons L, Belizán JM, Lauer JA, Betran AP, Meriald M, Althabe F. The global numbers and costs of additionally 
needed and unnecessary caesarean sections performed per year: overuse as a barrier to universal coverage. Geneve (SUI): World Health Report, Background Paper, 30; 2010. Disponível em: https://www.who.int/healthsystems/topics/ financing/healthreport/30C-sectioncosts.pdf

12. IBGE (Instituto Brasileiro de Geografia e Estatística). Censo Demográfico 2010. Nupcialidade, Fecundidade e Migração. Rio de Janeiro; 2012.

13. Marshall NE, Fu R, Guise J-M. Impact of multiple cesarean deliveries on maternal morbidity: a systematic review. Am J Obstet Gynecol. 2011; 205: 262.e1-8.

14. Dias MAB, Domingues RMSM, Schilithz AOC, NakamuraPereira M, CSG Diniz, Brum IR, Martins AL, Theme Filha MM, Gama SGN, Leal MC. Incidência do near miss materno no parto e pós-parto hospitalar: dados da pesquisa Nascer no Brasil. Cad Saúde Pública. 2014; 30 (suppl.): S169-S181.

15. Laws PJ, Li Z, Sullivan EA. Australia's mothers and babies 2008. Camberra; 2010. (Perinatal statistics series; 24)

16. Martin JA, Hamilton BE, Sutton PD, Ventura SJ, Mathews TJ, Kirmeyer S, Osterman MJK. Births: Final data for 2007. Natl Vital Stat Rep. 2010; 58 (24): 1-85. Disponível em: http://www.cdc.gov/nchs/data/nvsr/nvsr58/nvsr58 24.pdf.

17. Domingues RMSM, Dias MAB, Nakamura-Pereira M Torres JA, d'Orsi E, Pereira AP. Processo de decisão pelo tipo de parto no Brasil: da preferência inicial das mulheres à via de parto final. Cad Saúde Pública. 2014; 30: S101-16.

18. Guise J-M, Denman MA, Emeis C, Marshall N, Walker M, $\mathrm{Fu} \mathrm{R}$, Janik R, Nygren P, Eden KB, McDonagh M. Vaginal Birth After Cesarean: New Insights on Maternal and Neonatal Outcomes. Obstet Gynecol. 2010; 115: 1267-78.

19. Lopez E, Patkai J, Ayoubi ME, Jarreau P-H. Bénéfices et risques néonataux de la tentative de voie basse comparée à la césarienne programmée en cas d'antécédent de césarienne. J Gynecol Obstet Biol Reprod. 2012;41:727-734

20. Rozen G, Ugoni AM, Sheehan PM. A new perspective on VBAC: A retrospective cohort study. Women Birth. 2011; 24: 3-9.

21. Berquó E, Cavenaghi S. Direitos reprodutivos de mulheres e homens face à nova legislação sobre esterilização voluntária. Cad Saúde Pública. 2003; 19 (Supl 2): S441-53.
22. Carvalho LEC, Osis MJD, Cecatti JG, Bento SF, Manfrinati MB. Esterilização cirúrgica voluntária na Região Metropolitana de Campinas, São Paulo, Brasil, antes e após sua regulamentação. Cad Saúde Pública. 2007; 23 (12): 2906-16.

23. Guimarães EAA, Vieira CS, Nunes FDD, Januário GC, Oliveira VC, Tibúrcio JD. Prevalência e fatores associados à prematuridade em Divinópolis, Minas Gerais, 2008-2011: análise do Sistema de Informações sobre Nascidos Vivos. Epidemiol Serv Saúde. 2017; 26 (1): 91-8.

24. Torres JA, Domingues RMSM, Sandall J, Hartz Z, da Gama SGN, Theme Filha MM. Cesariana e resultados neonatais em hospitais privados no Brasil: estudo comparativo de dois diferentes modelos de atenção perinatal. Cad Saúde Pública. 2014; 30: S220-31.

25. Brasil. Ministério da Saúde. Secretaria de Vigilância em Saúde. Departamento de Análise de Situação em Saúde. Saúde Brasil 2013: uma análise da situação de saúde e das doenças transmissíveis relacionadas à pobreza. Brasília, DF; 2014.

26. Spong CY. Defining “Term” Pregnancy: Recommendations From the Defining "Term" Pregnancy Workgroup. JAMA. 2013; 309 (23): 2445-6.

27. Chiossi G, Lai Y, Landon MB, Spong CY, Rouse DJ, Varner MW, Caritis SN, Sorokin Y, O'Sullivan MJ, Sibai BM, Thorp JM, Ramin SM, Mercer BM. Timing of delivery and adverse outcomes in term singleton repeat cesarean deliveries. Obstet Gynecol. 2013; 121: 561-9.

28. Dahlen HG, Tracy S, Tracy M, Bisits A, Brown C, Thornton C. Rates of obstetric intervention among low-risk women giving birth in private and public hospitals in NSW: a population-based descriptive study. BMJ Open. 2012; 2: 1-8.

29. Bonilha EA, Vico ESR, Freitas M, Barbuscia DM, Galleguillos TGB, Okamura MN, Santos PC, Lira MMTA, Torloni MR. Cobertura, completude e confiabilidade das informações do Sistema de Informações sobre Nascidos Vivos de maternidades da rede pública no município de São Paulo, 2011. Epidemiol Serv Saúde. 2018; 27 (1): e201712811.

Received on August 18, 2020

Final version presented on December 15, 2020

Approved on February 19, 2021 